\title{
Liquefaction-fluidization induced land subsidence: impact of the 2011 Tohoku earthquake on reclaimed land around Tokyo bay area, Japan
}

\author{
A. Kagawa, K. Furuno, T. Kusuda, Y. Sakai, T. Yoshida, and O. Kazaoka \\ Research Institute of Environmental Geology, Chiba (RIEGC), 3-5-1 Inagekaigan, Mihama, Chiba city, Japan
}

Correspondence to: A. Kagawa (kagawaa2016@gmail.com)

Published: 12 November 2015

\begin{abstract}
The 2011 Tohoku earthquake caused major liquefaction-induced, ground deformation of the reclaimed land surrounding Tokyo Bay. In this area, liquefaction was visibly manifest by sand boils, ejection of sandy water, land subsidence and floating underground tanks. The level measurements show a correspondence between the degree of liquefaction-fluidization and the amount of subsidence. The strata most susceptible to liquefaction are hydraulically emplaced dredged fill and artificial strata on thick uncompacted Holocene deposits. On the other hand, the phenomena of seismic isolation coursed by liquefaction had saved the single-family houses from collapse.
\end{abstract}

\section{Introduction}

The 2011 off the Pacific coast of Tohoku Earthquake caused heavy damage by Tsunami and geologic disaster on east Japan. Tokyo bay area is underlain by hydraulically emplaced dredged fill and artificial strata resting on thick uncompacted Holocene deposits. In this area, liquefaction was visibly manifest by sand boils, ejection of muddy groundwater, land subsidence and floating underground tanks. In partly, the banks on the edge of the reclaimed lands had broken by the outflowing boiled sand pressure. The authors have investigated liquefaction-induced phenomena in southeast part of the Kanto Groundwater Basin, and report the disaster of Urayasu City on north part of Tokyo bay area (Fig. 1).

\section{Level measurements}

Urayasu city, located along the northeast coast of the Tokyo bay, is composed of Holocene deltaic strata and man-made strata (Fig. 2). The authors surveyed by levelling the elevation differences of a number of the benchmarks before (2010) and after (2011) the earthquake. The results show that about $4 \mathrm{~cm}$ of subsidence developed in the area with Holocene deposits, and more than $17 \mathrm{~cm}$ in the reclaimed land (Fig. 3). Moreover, the authors investigated the differences between
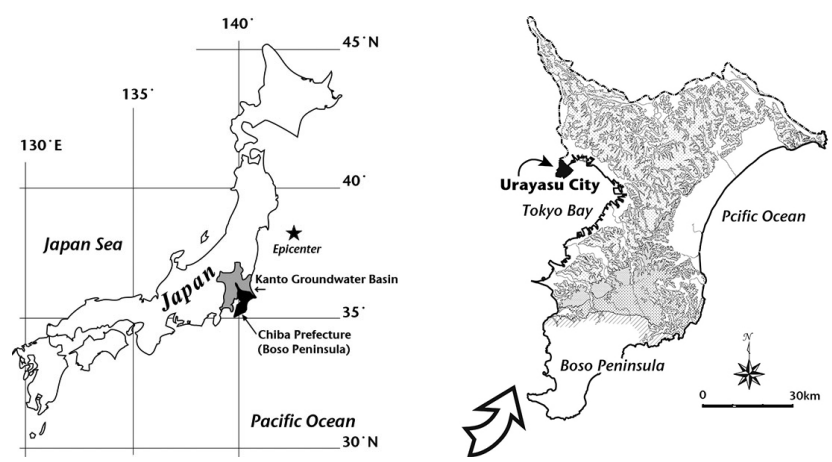

Figure 1. Location of Urayasu City and the epicenter of the 2011 Tohoku earthquake.

land subsidence of the ground level and the remains of the pre-earthquake surface in correspondence of the piled buildings (Fig. 4). The value of subsidence is representative of the degree of liquefaction-fluidization. 


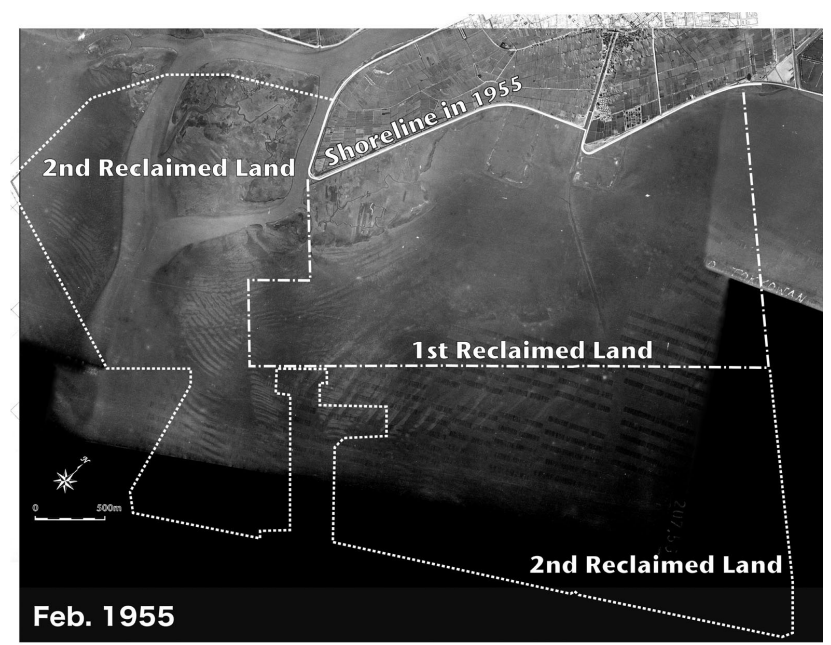

Figure 2. Original shoreline and the reclaimed land in Urayasu City (The aerial photo by Kokusai-kogyo co. ltd.).

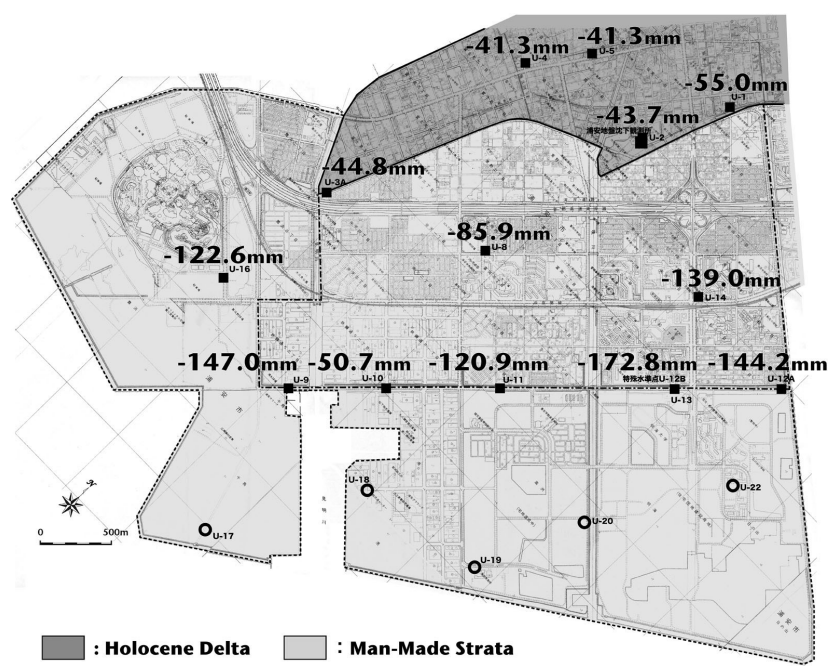

Figure 3. Elevation change of bench marks in Urayasu City (January 2011-2012).

\section{Chidori block - the latest reclaimed land in Urayasu city}

Chidori block, located in the southeast part of Urayasu city, is the latest hydraulically emplaced dredged fill, and has been used for the logistic warehouse and the incinerating office. This area has struck the severe liquefaction-fluidization hazards, land subsiding, sand boiling, telegraph poles tilting and broken road (Fig. 5). At the center of the Chidori block, land subsidence reached $95 \mathrm{~cm}$. The historic aerial photographs show a correspondence between the dredged trench and the rates of subsidence (Fig. 6). The differences between the thickness of the man-made strata and Holocene sediments played an important role on the subsidence amount and distribution (Fig. 7).

\section{Conclusions}

The 2011 Tohoku earthquake caused major liquefaction and, ground deformation of the reclaimed land surrounding Tokyo Bay. In this area, liquefaction was visibly manifest by sand boils, ejection of sandy water, land subsidence and floating underground tanks. The banks on the edge of the reclaimed lands partially broke by the outflowing boiled sand pressure. Based on surface benchmarks and subsurface markers on 10-m deep piles, near-surface compaction was quantified in about $14 \mathrm{~cm}$. Locally, land subsidence reached $95 \mathrm{~cm}$. The level measurements show a correspondence between the degree of liquefaction-fluidization and the amount of subsidence. The strata most susceptible to liquefaction are hydraulically emplaced dredged fill and artificial strata on thick uncompacted Holocene deposits. Much reclaimed land around Tokyo Bay had been densely urbanized, thus land 


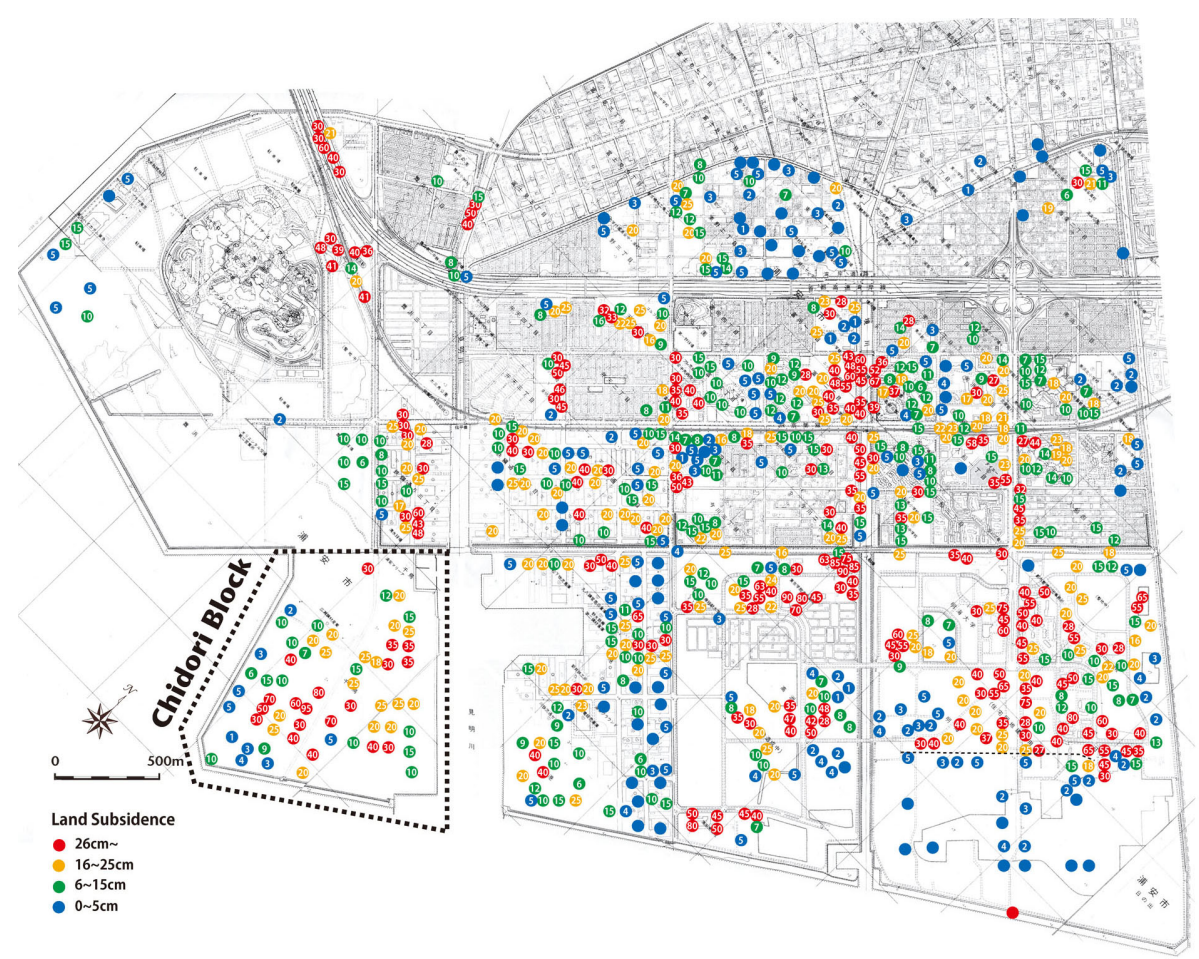

Figure 4. Values of land subsidence caused by the 2011 Tohoku earthquake in Urayasu City (RIEGC, 2011).

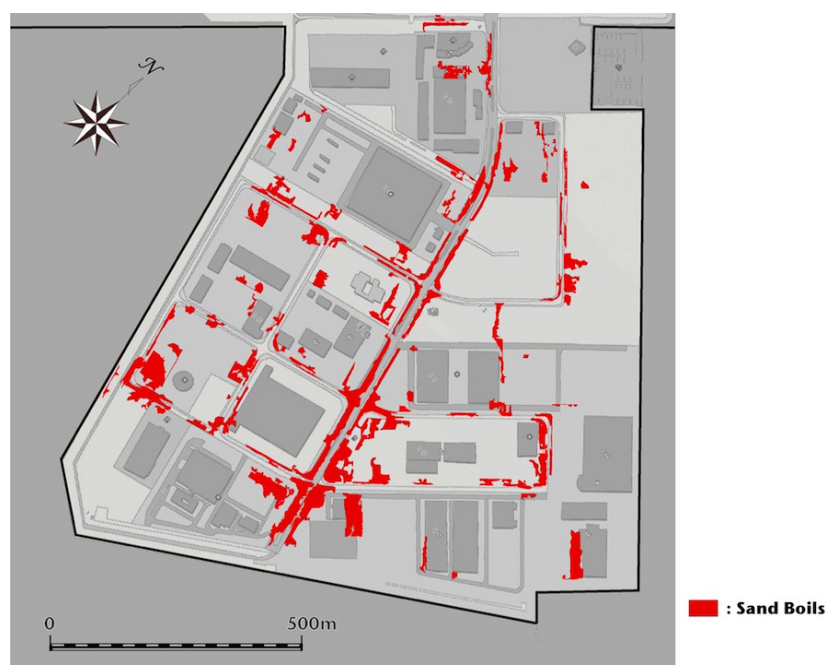

Figure 5. Distribution of sand boils in Chidori block, Urayasu City (RIEGC, 2011). 


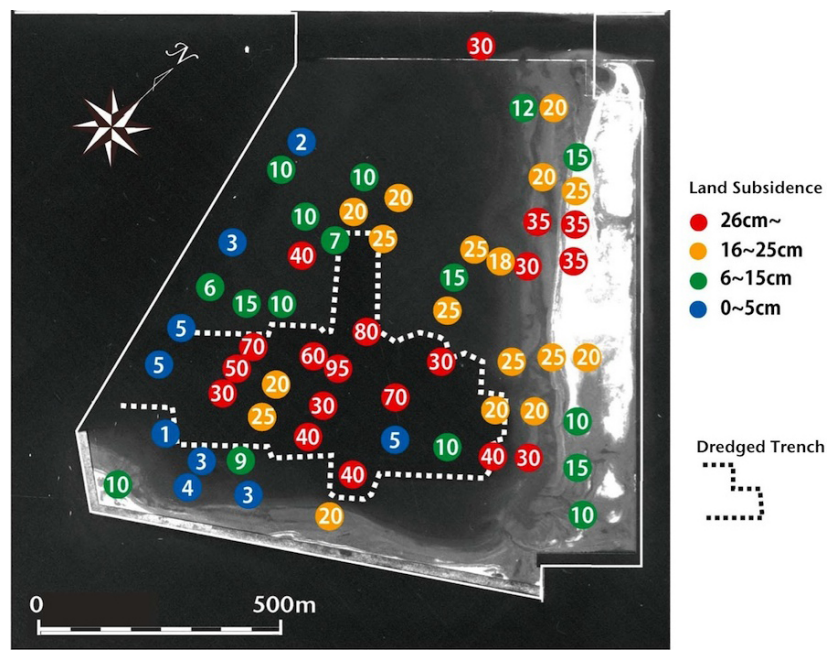

Figure 6. Subsidence values and dredged trench in Chidori block, Urayasu City (RIEGC, 2011).

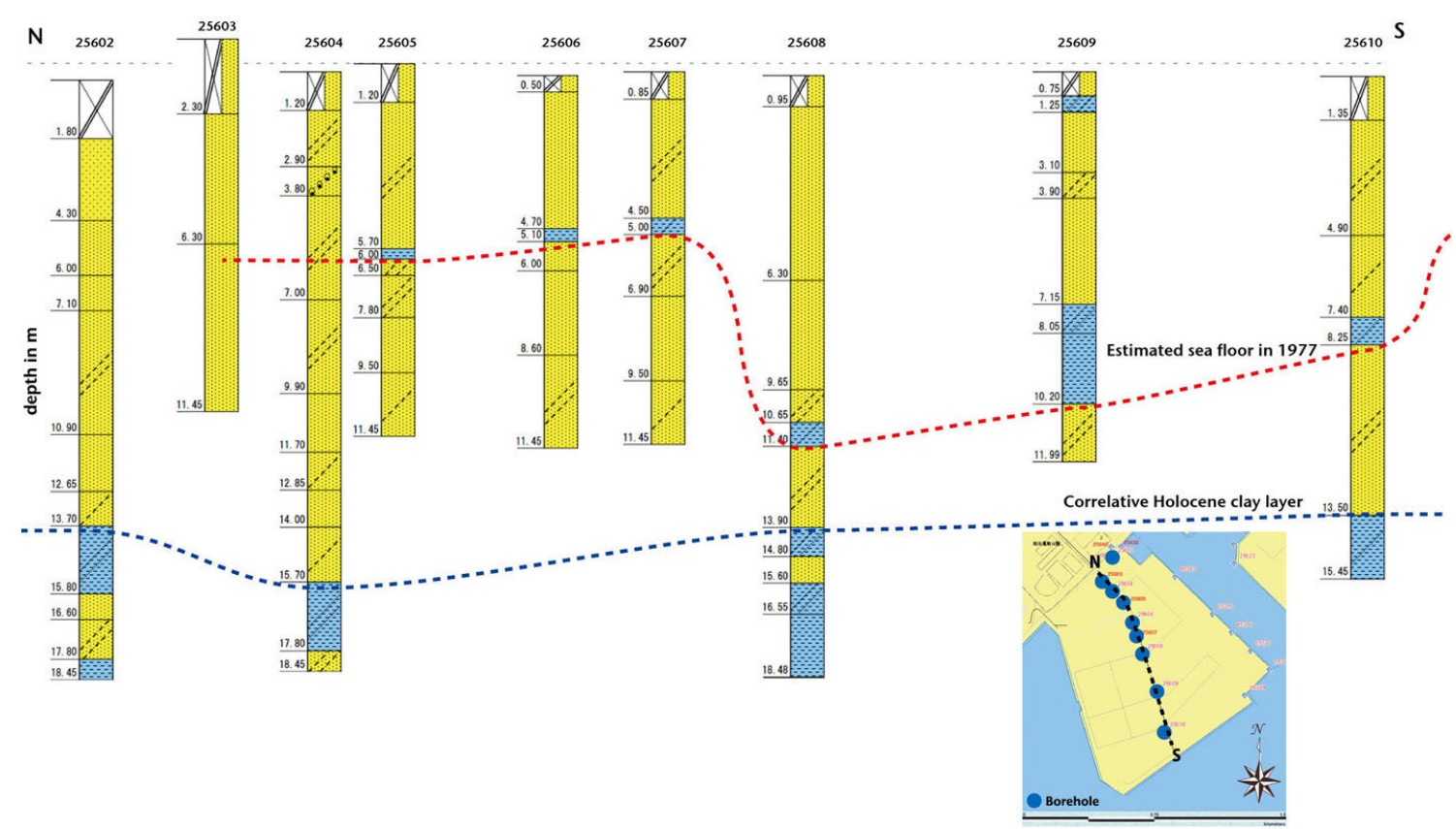

Figure 7. Geologic section in Chidori block, Urayasu City (RIEGC, 2011).

subsidence caused major damage to structures and infrastructure. On the other hand, the phenomena of seismic isolation coursed by liquefaction had saved the single-family houses from collapse (Kagawa et al., 2000). Seismically induced liquefaction may be not a rare event, and its impact on watersaturated man-made strata and reclaimed land is inherently costly.

Acknowledgements. We sincerely appreciate colleague of Research Institute of Environmental Geology, Chiba who have investigated the liquefaction-fluidization hazards with us.

\section{References}

Kagawa, A., Furuno, K., Kusuda, T., Satoh, K., Sakai,Y., Kamura, K., Kazaoka, O., Morisaki, M., and Nirei, H.: Land Subsidence in artificial islands due to liquefaction caused by the Kobe Earthquake in 1995, Japan, Proceedings of the Sixth International Symposium on Land Subsidence, 45-51, 2000.

Research Institute of Environmental Geology, Chiba, Japan: Investigation report of liquefaction-fluidization phenomena caused by The 2011 off the Pacific coast of Tohoku earthquake in Chiba prefecture, No.G-8, 2011. 